\section{OPEN ACCESS}

Edited by:

Eugene Dempsey,

University College Cork, Ireland

Reviewed by:

Britt Nakstad,

University of Oslo, Norway

Jon Dorling,

Dalhousie University, Canada

Anup C. Katheria

Sharp Mary Birch Hospital for Women and Newborns, United States

*Correspondence:

Georg M. Schmölzer georg.schmoelzer@me.com

Specialty section:

This article was submitted to

Neonatology,

a section of the journal

Frontiers in Pediatrics

Received: 04 July 2018 Accepted: 19 September 2018 Published: 16 October 2018

Citation:

Viaroli F, Cheung P-Y, O'Reilly M,

Polglase GR, Pichler $G$ and Schmölzer GM (2018) Reducing Brain Injury of Preterm Infants in the Delivery

Room. Front. Pediatr. 6:290

doi: 10.3389/fped.2018.00290

\title{
Reducing Brain Injury of Preterm Infants in the Delivery Room
}

\section{Francesca Viaroli 1,2, Po-Yin Cheung 1,2, Megan O'Reilly ${ }^{1,2}$, Graeme R. Polglase ${ }^{3}$, Gerhard Pichler ${ }^{4}$ and Georg M. Schmölzer ${ }^{1,2 *}$}

${ }^{1}$ Centre for the Studies of Asphyxia and Resuscitation, Royal Alexandra Hospital, Edmonton, AB, Canada, ${ }^{2}$ Department of Pediatrics, University of Alberta, Edmonton, AB, Canada, ${ }^{3}$ The Ritchie Centre, Hudson Institute of Medical Research and Department of Obstetrics and Gynaecology, Monash University, Melbourne, VIC, Australia, ${ }^{4}$ Department of Pediatrics, Medical University Graz, Graz, Austria

Cerebrovascular injury is one of the major detrimental consequences of preterm birth. Recent studies have focused their attention on factors that contribute to the development of brain lesions immediately after birth. Among those factors, hypothermia and lower cerebral oxygen saturation during delivery room resuscitation and high tidal volumes delivered during respiratory support are associated with increased risk of severe neurologic injury. In preterm infants, knowledge about causes and prevention of brain injury must be applied before and at birth. Preventive and therapeutic approaches, including correct timing of cord clamping, monitoring of physiological changes during delivery room resuscitation using pulse oximetry, respiratory function monitoring, near infrared spectroscopy, and alpha EEG, may minimize brain injury, Furthermore, postnatal administration of caffeine or other potential novel treatments (e.g., proangiogenic therapies, antioxidants, hormones, or stem cells) might improve long-term neurodevelopmental outcomes in preterm infants.

Keywords: infants, newborn, neonatal resuscitation, very low birth weight infants, brain injury, intraventricular hemorrhage

\section{INTRODUCTION}

Cerebrovascular lesions including hemorrhagic and ischemic injuries are major detrimental consequences of preterm birth resulting in adverse neurodevelopmental outcomes. There is increasing evidence that fluctuations in cerebral blood flow and regional cerebral oxygenation, delivery of respiratory support, and changes in temperature in the delivery room (DR) initiates an inflammatory cascade leading to brain injury (1-3). The premature brain is vulnerable to oxidative stress from hypoxic-ischemic injury, which depends on heart-rate/cardiac output, immature vascular supply, and impairment in vascular autoregulation (4). In this review, we describe what is known about the factors involved in the development of brain injury during fetal-to-neonatal transition at birth. Furthermore, we discuss potential preventive and therapeutic approaches, which might help to minimize brain injury during neonatal resuscitation.

\section{TEMPERATURE}

The World Health Organization (WHO) defines hypothermia in newborn infants as (i) cold stress or mild hypothermia between 36.0 and $36.4^{\circ} \mathrm{C}\left(96.8-97.5^{\circ} \mathrm{F}\right)$, (ii) moderate hypothermia between 
32.0 and $35.9^{\circ} \mathrm{C}\left(89.6-96.6^{\circ} \mathrm{F}\right)$, and (iii) severe hypothermia $<32^{\circ} \mathrm{C}\left(89.6^{\circ} \mathrm{F}\right)(5)$. The $\mathrm{WHO}$ recommend that the temperature of healthy newborns should be maintained between 36.7 and $37.7^{\circ} \mathrm{C}$, as a decrease in body temperature by one degree will increase mortality by $\sim 28 \%$ (5). Moderate hypothermia can further result in lower partial pressure of arterial oxygen, metabolic acidosis, and an increased risk of intraventricular hemorrhage (IVH) $(6,7)$.

Preterm infants are at risk of hypothermia because of their large surface area to body mass ratio, thin and immature skin, and a lack of brown adipose tissue. Standard delivery room practices to prevent heat loss include (i) set ambient temperature, (ii) polyethylene occlusive wraps, and (iii) exothermic mattresses for preterm infants less than 32 weeks' gestation (8). A recent study by Garcia-Munoz Rodrigo et al. (6) reported increased mortality and rates of IVH ( $\geq$ grade III) in 635 infants born less than 30 weeks' gestation with hypothermia at Neonatal Intensive Care Unit (NICU) admission. This is concerning as hypothermia rates remain high in this population, with $40-50 \%$ of extreme low birth weight (ELBW) infants presenting with a core temperature below $36.0^{\circ} \mathrm{C}$ upon admission to the $\operatorname{NICU}(9,10)$.

A relatively overlooked aspect of heat loss in the DR is the use of unconditioned gases during respiratory support. Unconditioned gases are "cold and dry," typically room temperature $\left(23^{\circ} \mathrm{C}\right)$ with very low relative humidity $(2-5 \%$; ambient relative humidity is usually $30-40 \%)$ (11). This differs from standard practice in the NICU where medical gases are heated and humidified (conditioned) during respiratory support (11). A cohort study by te Pas et al. compared 112 infants $<32$ weeks' gestation before (the "cold" cohort) and after (the "heated" cohort) the introduction of heated and humidified gases during respiratory support at birth (12). The study reported significantly improved NICU admission temperature following the use of heated and humidified gases in the DR. Furthermore, a trial by the same group in 203 infants $<32$ weeks' gestation reported an $\sim 50 \%$ reduction in rates of major IVH (grades III and IV) 5 vs. $9.5 \%$ in infants randomized to conditioned gases compared to unconditioned gases, respectively (13). Similarly, McGrory et al. randomized infants born 30 weeks' gestation to conditioned or unconditioned gases and reported a $66 \%$ reduction in IVH in the conditioned group (11). These data suggest that respiratory support in the DR should be provided using conditioned gases to reduce risk of brain injury.

\section{OXYGEN SATURATION}

Immediately after birth arterial oxygen saturation $\left(\mathrm{SpO}_{2}\right)$ values in the newborn could be as low as $30 \%$ (14), which then increase over the next $7-10 \mathrm{~min}$ to $85-95 \%$ (15). In 2010 , the resuscitation guidelines were revised to initiate the resuscitation

Abbreviations: $\mathrm{SpO}_{2}$, Oxygen saturation; IVH, Intraventricular hemorrhage; NICU, Neonatal Intensive Care Unit; ELBW, Extreme low birth weight; PPV, Positive pressure ventilation; DR, Delivery room; $\mathrm{V}_{\mathrm{T}}$, Tidal volume; aEEG, AlphaEEG; NIRS, Near-Infrared spectroscopy; DCC, Delayed cord clamping; ICC, Immediate cord clamping; UCM, Umbilical cord milking; $\mathrm{rScO} 2$, Cerebral oxygen saturation; FTOE, Cerebral oxygen extraction; $\mathrm{MgSO}_{4}$, Magnesium sulfate. of term infants using air, and either air or $<65 \%$ oxygen for preterm infants (16). Subsequently oxygen concentrations should be adjusted to meet $\mathrm{SpO}_{2}$ ranges, which are similar to those of spontaneously breathing, healthy full-term infants. However, the change to using lower oxygen concentration is based on limited evidence. Indeed, in a post hoc analysis the TO2RPIDO trial (17) reported that infants $<28$ weeks' gestation receiving initially air had an almost four-fold increased risk of death [RA: 10 of 46 [22\%]] compared with those given 100\% oxygen. Similarly, Rook et al. compared 30 vs. $65 \%$ oxygen and reported a significantly faster time to reach an $\mathrm{SpO}_{2}$ of $88 \%$ [median (IQR) 3:14 (2:08-5:24) vs. 5:45 (3:49-7:51) $\mathrm{min}]$ (18). This is important as a recent individual patient analysis of eight trials demonstrated that $46 \%$ of preterm infants resuscitated with an initial low oxygen concentration did not reach $\mathrm{SpO}_{2}$ of $80 \%$ at $5 \mathrm{~min}$, which was associated with increased risk of major IVH (19). Of interest, while it took a longer time to achieve the target $\mathrm{SpO}_{2}$ when low oxygen concentration was initiated in the resuscitation, there was an almost five times higher risk of death when there was bradycardia at 5 min of life. Furthermore, a review of a Canadian population of infants $<29$ weeks' gestation reported a higher risk of severe neurologic injury or death when resuscitation was started with low oxygen (20). Similarly, a recent survey of 630 clinicians from 25 countries reported that the majority would initiate preterm infant DR stabilization using 30-40\% oxygen (16). These data suggest that if lower starting oxygen concentrations are used, a potentially more aggressive oxygen titration would be required to avoid hypoxia (as well as hyperoxia) that is associated with IVH or brain injury. Initial low oxygen concentration during resuscitation might not be optimal and large trials are urgently needed to address this knowledge gap. Most recently PRESOX (NCT01773746) comparing 21 vs. $60 \%$ oxygen at birth has been halted due to lack of recruitment. The STARTPreterm (NCT03115463) and TORPIDO2 ACTRN12615000115538) trials are currently ongoing to address optimized targeted oxygen strategies during DR resuscitation and their effects on developmental outcome.

\section{CEREBRAL TISSUE OXYGENATION}

Arterial $\mathrm{SpO}_{2}$ and heart rate are routinely used to assess oxygen delivery and oxygen consumption for preterm infants. However, both parameters only indirectly assess cerebral oxygen demand. Tissue oxygenation is influenced by oxygen delivery and oxygen consumption, where oxygen delivery could be affected by changes in $\mathrm{SpO}_{2}$, arterial hemoglobin content, and cerebral perfusion. Cerebral perfusion itself relies on adequate cardiac output and regional vascular resistance, where cerebral vascular resistance is affected by autoregulatory capacities. Routine $\mathrm{SpO}_{2}$ monitoring alone only assesses the oxygen saturation of the arterial blood which reaches the brain, therefore it does not reflect oxygen delivery, which is also dependent on perfusion and hemoglobin content. Near-Infrared spectroscopy (NIRS) assesses the difference in absorption of near-infrared light by oxy- and deoxyhemoglobin to measure the oxygen saturation in regional tissue. This allows for a continuous non-invasive 
measurement of regional cerebral oxygen saturation ( $\mathrm{crSO} 2$ ) and cerebral oxygen extraction (FTOE) (21). Reference ranges of $\mathrm{rScO} 2$ and $\mathrm{FTOE}$ in term and preterm infants requiring no medical support during transition immediately after birth have been established (22): in all neonates, median $\mathrm{crSO} 2$ was $41 \%$ (23-64) at $2 \mathrm{~min}, 68 \%(45-85)$ at $5 \mathrm{~min}, 79 \%(65-90)$ at $10 \mathrm{~min}$, and $77 \%(63-89)$ at 15 min of age. In Pichler's study, infants with IVH had significantly lower cerebral oxygenation compared to infants without IVH, whereas $\mathrm{SpO}_{2}$ was similar especially after $10 \mathrm{~min}$ in both groups. This is further supported by a recent randomized trial comparing oxygen titration using NIRS and $\mathrm{SpO}_{2}$ vs. $\mathrm{SpO}_{2}$ alone (23). Overall, the burden of cerebral hypoxia in was halved when titration was done based on NIRS and $\mathrm{SpO}_{2}$, and a trend to lower mortality and cerebral injury in NIRS and $\mathrm{SpO}_{2}$ group was observed (23). Furthermore, the SafeboosC study compared cerebral NIRS monitoring in combination with a dedicated treatment guideline during the first $72 \mathrm{~h}$ of life to blinded NIRS oxygenation monitoring with standard care in infants $<28$ weeks' gestation (24). The 86 infants randomized to the NIRS group had a $58 \%$ (95\% confidence interval $35-$ $73 \%, P<0.001)$ reduction in their burden of hypoxia and hyperoxia compared with the control group, but no difference in their long-term-outcome. Taken together, cerebral oxygenation could be optimized using a dedicated treatment guideline in combination with cerebral NIRS monitoring (24). A recent twocenter observational cohort study reported that infants $<32$ weeks' gestation with low $\mathrm{crSO}_{2}$-values had significantly higher rates of IVH compared to infants with normal $\mathrm{CrSO}_{2}$ values (25). Furthermore, there is increasing evidence that cerebral tissue oxygenation is significantly lower when resuscitation interventions are needed compared to unassisted transition (26). In addition, cerebral FTOE values were significantly elevated in infants receiving respiratory support, suggesting compensation for a lower cerebral oxygen delivery (27). These data suggest that additional monitoring using $\mathrm{crSO}_{2}$ during the immediate transition period might reduce the risk of developing IVH. Monitoring oxygen delivery using arterial pulse oximetry alone might be insufficient to identify preterm infants with cerebral hypoxia and at risk for IVH. Adding NIRS monitoring might reduce cerebral hypoxia and the incidence of premature infants developing IVH. A large trial is currently underway (COSGOD III-NCT03166722) to address this knowledge gap (28).

\section{TIDAL VOLUME}

Most preterm infants born $<28$ weeks' gestation require some form of respiratory support in the DR (29), which is commonly delivered using positive pressure ventilation (PPV). During PPV a fixed pressure is chosen with the assumption it will deliver an adequate tidal volume $\left(\mathrm{V}_{\mathrm{T}}\right)$, but the $\mathrm{V}_{\mathrm{T}}$ is rarely measured (8). There is ample evidence that high $\mathrm{V}_{\mathrm{T}}$ delivery during PPV causes ventilator-induced lung injury $(30,31)$. In addition, several animal studies reported that the delivery of $\mathrm{V}_{\mathrm{T}}>8 \mathrm{~mL} / \mathrm{kg}$ causes ventilation induced brain injuries (VIBI) in preterm infants $(2,3,32)$. Polglase et al. (32) reported that a high $\mathrm{V}_{\mathrm{T}}$ strategy $\left(\mathrm{V}_{\mathrm{T}}\right.$ of $>8 \mathrm{~mL} / \mathrm{kg}$ ) compared to a low $\mathrm{V}_{\mathrm{T}}$ strategy $\left(\mathrm{V}_{\mathrm{T}}\right.$ of $5-7 \mathrm{~mL} / \mathrm{kg}$ ) during initial resuscitation in preterm lambs causes increased cerebral hemodynamic instability, increased brain inflammation, oxidative stress, and vascular extravasation. These changes are related to up-regulation of systemic pro-inflammatory cytokines (e.g., IL-1b, IL-6, and TNF-a), which compromises the integrity of the blood-brain-barrier and neurovascular circulation $(2,3,32)$. In a recent observational study in 165 preterm infants $<29$ weeks' gestation, Mian et al. (1) observed a four-fold increase in IVH in preterm infants ventilated with $\mathrm{V}_{\mathrm{T}}>6 \mathrm{~mL} / \mathrm{kg}^{1}$. Indeed, $75 \%$ of included infants had high $\mathrm{V}_{\mathrm{T}}$ and $41(25 \%)$ normal $\mathrm{V}_{\mathrm{T}}$. Overall, severe IVH (grade III or IV) developed in $33 / 124(27 \%)$ infants in the high $\mathrm{V}_{\mathrm{T}}$ group and 2/41 (6\%) in the normal $\mathrm{V}_{\mathrm{T}}$ group $(P=0.01)$. These results are supported by animal studies in preterm lambs who reported an increase in brain inflammation, oxidative stress, vascular extravasation, and brain inflammation when using $\mathrm{V}_{\mathrm{T}}>8 \mathrm{~mL} / \mathrm{kg}$ during initial resuscitation. Despite the causative relationship between $V_{T}$ and IVH remains to be determined, it is prudent to investigate if using direct feedback systems (e.g., a respiratory function monitor) would help minimize VIBI in preterm infants.

\section{IMPLEMENTING AVAILABLE KNOWLEDGE}

Implementation of knowledge regarding the causes of brain injury in the preterm infant should be initiated at birth, rather than later when admitted into the NICU, as this may be the key to prevention.

\section{Placental Transfusion and Cord Management}

The optimal timing for clamping the umbilical cord after birth in preterm infants remains unclear. For centuries, delayed cord clamping (DCC) was practiced until a change in the 1950's to immediate cord clamping (ICC), which allowed a rapid transfer of the newborn to neonatal clinicians. However, ICC is associated with significantly lower preload and afterload, higher pulmonary vascular resistance, persistent right-to-left atrial and ductal shunting, and fluctuations in cerebral blood pressure and cerebral blood flow, which might cause cerebral ischemia or hemorrhage (33). This is supported by several animal studies demonstrating that DCC results in improved cardiovascular and cerebral stability (33-35). Furthermore, randomized trials and meta-analyses reported a trend of reducing major IVH, in addition to a significant reduction in mortality, with DCC compared to ICC $(36,37)$. Alternatively, umbilical cord milking (UCM), which allows for rapid transfer of blood from the placenta to the infant (38), has been proposed. A recent animal study raised concerns about the hemodynamic and cerebral effects of UCM and reported that UCM without placental refill failed to provide placental transfusion, and UCM strategies caused considerable hemodynamic disturbances in carotid artery blood flow and systemic blood pressure without increasing pulmonary blood flow (33). The study concluded that UCM does not provide the same physiological benefits as physiologicalbased cord clamping. However, a recent trial comparing UCM with DCC reported higher hemoglobin, first infants' temperature 
in the DR, and systemic blood flow with UCM in preterm infants (39). Furthermore, infants randomized to UCM had higher language and cognitive scores compared to DCC, and similar rates of mild or moderate to severe neurodevelopmental impairment (40). These data are very promising and the currently ongoing larger trials including PREMOD2 (NCT03019367) in $23^{+0}$ to $31^{+6}$ and MINVI (NCT03631940) in $35^{+0}$ to $41^{+6}$ weeks' gestation will provide a more definite answer.

More recently, animal data suggest that initiating ventilation prior to umbilical cord clamping increases pulmonary blood flow, and subsequently left ventricular output, and improves arterial and cerebral oxygenation, therefore leading to a smoother cardiovascular transition $(34,35,41)$. Initiating ventilation prior to umbilical cord clamping in preterm infants is feasible and safe (42-44). In addition, none of the initiating ventilation prior to umbilical cord clamping human clinical trials have reported any beneficial outcomes. Therefore, larger studies adequately powered to examine important short- and long-term outcomes are needed (45). The currently ongoing study (Vent FIRSTNCT02742454) will examine some of these outcomes.

\section{Monitoring}

\section{Respiratory Function Monitoring}

During mask ventilation in the DR, large and variable $\mathrm{V}_{\mathrm{T}} \mathrm{s}$ are often delivered (46-54). Schmölzer et al. reported a median (IQR) $\mathrm{V}_{\mathrm{T}}$ of $8.7 \mathrm{ml} / \mathrm{kg}(5.3-11.3)$ which varied widely during each resuscitation and between resuscitators $(46,49,50)$. Similarly, Kaufman et al reported median $\mathrm{V}_{\mathrm{T}}$ s of 8.3-9.3 mL/kg during PPV (47). These $\mathrm{V}_{\mathrm{T}} \mathrm{s}$ were significantly larger compared to $\mathrm{V}_{\mathrm{T}} \mathrm{s}$ during spontaneous breathing $(52,55,56)$. Furthermore, van Vonderen et al (54) reported a median (IQR) $\mathrm{V}_{\mathrm{T}}$ of $8.3(6.8-15.4)$ during mask PPV in preterm infants $<32$ weeks' gestation in the DR. Using a respiratory function monitor (RFM) would allow for an objective assessment of mask PPV (48, 50, 51, 53). Despite the technicality in its application, a RFM would provide real-time information of mask leak, airway obstruction, and $\mathrm{V}_{\mathrm{T}}$ delivery which are important in neonatal resuscitation and ventilatory support (48). A small randomized trial comparing the display of a RFM visible or masked reported lower rate of excessive $V_{T}$ in the infants with the RFM visible (57). However, the trial included all infants $<32$ weeks' and therefore did not report any difference in brain injury. Trials examining if an RFM would decrease rates of IVH during PPV in the DR are urgently needed.

\section{Closed-loop Automatic Oxygen Control}

Premature infants often require oxygen supplementation immediately after birth to achieve oxygen saturation targets and to avoid hypoxemia. However, the titration of oxygen often leads to hyperoxemia, which causes systemic and tissue oxidative stress and can impair long-term outcomes (58-61). Preterm infants are monitored using pulse oximetry to adjust the fraction of inspired oxygen $\left(\mathrm{FiO}_{2}\right)$ to reach the targeted oxygen saturation. Recently, closed loop $\mathrm{FiO}_{2}$ systems have been utilized, which consist of an oxygenation monitoring device or pulse oximeter, a gas delivery device, and an algorithm that determines the timing, degree, and frequency of each $\mathrm{FiO}_{2}$ adjustment to keep $\mathrm{SpO}_{2}$ within target range set by the clinician. The closed loop $\mathrm{FiO}_{2}$ control systems minimize exposure to both high or low $\mathrm{O}_{2}$ levels and avoid large fluctuations in $\mathrm{SpO}_{2}$ levels. The CLAC trial (62) randomized 34 preterm infants $<37$ weeks' gestation to routine manual control (RMC) or RMC supported by CLAC using a cross-over design for 24-h periods. Overall, the median time with arterial oxygen saturation levels within target range was $61.4 \%$ for RMC and $71.2 \%$ for CLAC $(p<0.001)$. Also, the median (range) number of manual $\mathrm{FiO}_{2}$ adjustments was significantly reduced for RMC compared to CLAC (77 vs. $52 \%$, respectively; $p=0.007$ ). A recent randomized cross-over trial in 41 preterm infants evaluated time spent within a predefined $\mathrm{SpO}_{2}$ alarm range using three different $\mathrm{SpO}_{2}$ target ranges (86-94\% vs. $88-92 \%$ vs. 89-91\%) during non-invasive respiratory support (63). Overall, the duration within the $\mathrm{SpO}_{2}$ target range and hyperoxemia was similar. However, duration of severe hypoxemia $\left(\mathrm{SpO}_{2}<80 \%\right)$ was significantly reduced when $88-92 \%$ or $89-91 \%$ was used as a target range compared to $86-94 \%$, with $1.9,1.7$, and $3.4 \%(p$ $<0.001)$, respectively. This study suggests that a narrowing of the target range might reduce duration of hypoxemia, without increasing risk of hyperoxemia. However, no study has been performed in the DR and its role in optimizing systemic and tissue oxygenation remains unclear.

\section{Alpha-EEG}

Alpha-EEG (aEEG) provides a non-invasive continuous assessment of cerebral activity and recently there has been an increasing interest in monitoring cerebral activity during the fetal-to-neonatal transition and its' relationship with cerebral injury and long-term neurodevelopmental outcomes. Pichler et al showed that during immediate transition in infants $>34$ weeks' gestation, infants requiring resuscitation at birth showed a depressed cerebral activity along with cerebral oxygenation. Similarly, Tamussino et al. (64) reported that term infants with lower cerebral activity had lower cerebral oxygenation with increased cerebral oxygen extraction when compared to infants with normal aEEG values within the first $15 \mathrm{~min}$ after birth. As oxygen delivery and oxygen extraction is related to subsequent brain damage and long-term neurodevelopment impairment, cerebral monitoring combining aEEG and NIRS might allow for early identification of infants at risk of developing brain damage.

\section{Drugs \\ Caffeine}

Caffeine is routinely used to prevent apnea of prematurity, and it has been shown to improve neurodevelopmental impairment (65-67). The caffeine for apnea of prematurity trial by Schmidt et al. (67) reported reduced incidence of cerebral palsy (4.4 vs. $7.3 \%$; adjusted odds ratio, 0.58 ; 95\% CI, $0.39-0.87 ; p=0.009)$ and cognitive delay ( 33.8 vs. $38.3 \%$; adjusted odds ratio, $0.81 ; 95 \% \mathrm{CI}$, $0.66-0.99 ; p=0.04)$ in infants treated with caffeine compared to placebo (68).

In a recent pilot study by Katheria et al. (69) the administration of caffeine to 21 preterm neonates $<29$ weeks' gestation within $2 \mathrm{~h}$ after birth improved blood pressure $(p=$ 0.03 ) and systemic blood flow (superior vena cava flow, $p=0.04$ and right ventricular output, $p=0.03$ ) when compared to late administration (at $12 \mathrm{~h}$ of age), and there was no difference in 
the need for intubation $(p=0.08)$ or vasopressors $(p=0.21)$ by $12 \mathrm{~h}$ of age. Furthermore, Dekker et al. (70) showed that among preterm neonates $<29$ weeks' gestation a loading dose of caffeine in the DR significantly increased minute volume at $7-9 \mathrm{~min}$ after birth $(p<0.05)$ when compared to caffeine administration later in the NICU. Furthermore, there may be a neuroprotective effect of caffeine in the developing brain which is related to anti-inflammatory action, oxidative stress modulation $(65,66)$. Further studies in the early administration of caffeine regarding the benefits and impact on the developing brain are needed.

\section{Proangiogenic Therapies, Antioxidants, Hormones, and Stem Cells}

Proangiogenic therapies (e.g., vascular endothelial growth factor or fibroblast growth factor) (71), antioxidants (e.g., allopurinol, erythropoietin) (72-75), hormones (e.g., melatonin) (76), and stem cells or stem cell factors (77) have all been described as potential therapeutic strategies to promote functional recovery after brain injury. While these therapies seem promising, their application to reduce VIBI during the initial resuscitation in the DR is questionable and clinical trials are needed to confirm their feasibility, safety, and effectiveness.

\section{DISCUSSION}

There is increasing evidence that suboptimal management during the fetal to neonatal transition contributes to the development of preterm brain injury. Factors associated with preterm brain injury include hypothermia, hyperoxia with increased oxygen load and increased oxygen radicals, high $\mathrm{V}_{\mathrm{T}}$ delivery during $\mathrm{DR}$ resuscitation, and hypoxia with low cerebral tissue oxygenation. Improved DR care has the potential to improve short- and long-term outcomes of preterm infants.

It is important to ensure that the ambient temperature of DR is appropriate and infant's bed is properly prepared. Upon delivery of the preterm infant, DCC should be practiced. Studies are needed to optimize cord management by examining the effects of UCM or DCC on cerebral blood flow and hemodynamics or physiological based cord clamping (e.g., ventilation prior to cord clamping), which might improve cardiovascular transition and therefore reduce brain injury. The clinical team must

\section{REFERENCES}

1. Mian QN, Cheung P-Y, O’Reilly M, Barton SK, Polglase GR, Schmölzer GM. Impact of delivered tidal volume on the occurrence of intraventricular haemorrhage in preterm infants during positive pressure ventilation in the delivery room. Arch Dis Child Fetal Neonatal Ed. (2018) fetalneonatal-2017313864. doi: 10.1136/archdischild-2017-313864

2. Barton SK, Tolcos M, Miller SL, Roehr CC, Schmölzer GM, Davis PG, et al. Unraveling the links between the initiation of ventilation and brain injury in preterm infants. Front Pediatr. (2015) 10:97. doi: 10.3389/fped.2015. 00097

3. Barton SK, Tolcos M, Miller SL, Christoph-Roehr C, Schmölzer GM, Moss $\mathrm{TJ}$, et al. Ventilation-induced brain injury in preterm neonates: a review of potential therapies. Neonatology (2016) 110:155-62. doi: 10.1159/0004 44918 carefully monitor the infant's temperature and employ strategies (e.g., polyethylene bag, heating mattress) to reduce the risks of hypo- and hyperthermia. Supplemental oxygen should be given judiciously and guided by pulse oximetry and current oxygen targets to reduce exposure to hypoxia and hyperoxia. Similarly, adding NIRS might allow the clinical team to identify infants at risk of developing IVH through assessing cerebral tissue hypoxia/hyperoxia (78). When preterm infants fail to breathe adequately immediately after birth, adequate mask PPV will create a functional residual capacity and facilitate gas exchange. However, in order to reduce the risks of VIBI, the clinical team should avoid high $\mathrm{V}_{\mathrm{T}}$ delivery, which could be assisted by using a RFM.

At this time, the evidence is preliminary and long-term neurodevelopmental outcomes are lacking. This does not support a recommendation for monitoring of cerebral activity during the immediate transition after birth nor the postnatal administration of therapeutic drugs including caffeine and other potential agents.

\section{AUTHOR CONTRIBUTIONS}

GS and FV: conception and design; FV, GS, P-YC, MO'R, GRP and GP: collection and assembly of data, analysis and interpretation of the data, drafting of the article, critical revision of the article for important intellectual content, and final approval of the article.

\section{ACKNOWLEDGMENTS}

We would like to thank the public for donation of money to our funding agencies: GS is a recipient of the Heart and Stroke Foundation/University of Alberta Professorship of Neonatal Resuscitation, a National New Investigator of the Heart and Stroke Foundation Canada and an Alberta New Investigator of the Heart and Stroke Foundation Alberta. We would like to acknowledge support from the Women and Children's Health Research Institute, University of Alberta. GP is supported by a NHMRC and NHFA fellowship. The sponsors had no role in study design, data collection, data analysis, data interpretation, or writing of the report.
4. Vesoulis ZA, Mathur AM. Cerebral autoregulation, brain injury, and the transitioning premature infant. Front Pediatr. (2017) 5:64. doi: 10.3389/fped.2017.00064

5. March of Dimes, PMNCH, Save the Children, WHO. In: Howson CP, Kinney MV, Lawn JE, editors. Born Too Soon: The Global Action Report on Preterm Birth. Geneva: World Health Organization (2012).

6. Garcia-Munoz Rodrigo F, Rivero Rodriguez S, Siles Quesada C. Hypothermia risk factors in the very low weight newborn and associated morbidity and mortality in a neonatal care unit. An Pediatr. (2014) 80:144-50. doi: 10.1016/j.anpedi.2013.06.029

7. Miller SS, Lee HC, Gould JB. Hypothermia in very low birth weight infants: distribution, risk factors and outcomes. J Perinatol. (2011) 31(Suppl. 1):S49-56. doi: 10.1038/jp.2010.177

8. Wyckoff MH, Aziz K, Escobedo MB, Kapadia VS, Kattwinkel J, Perlman JM, et al. Part 13: neonatal resuscitation: 2015 american heart association 
guidelines update for cardiopulmonary resuscitation and emergency cardiovascular care. Circulation (2015) 132(18 Suppl. 2):S543-60. doi: 10.1161/CIR.0000000000000267

9. Laptook AR, Salhab W, Bhaskar B, Neonatal Research Network. Admission temperature of low birth weight infants: predictors and associated morbidities. Pediatrics (2007) 119:e643-9. doi: 10.1542/peds.2006-0943

10. Russo A, McCready M, Torres L, Theuriere C, Venturini S, Spaight M, et al. Reducing hypothermia in preterm infants following delivery. Pediatrics (2014) 133:e1055-62. doi: 10.1111/j.1442-200X.2010.03295.x

11. McGrory L, Owen LS, Thio M, Dawson JA, Rafferty AR, Malhotra A, et al. A randomized trial of conditioned or unconditioned gases for stabilizing preterm infants at birth. J Pediatr. (2018) 193:47-53. doi: 10.1016/j.jpeds.2017.09.006

12. te Pas AB, Lopriore E, Dito I, Morley CJ, Walther FJ. Heated air during stabilization at birth improves temperature in preterm infants. Pediatrics (2010) 125:e1427-32. doi: 10.1542/peds.2009-2656

13. Meyer MP, Hou D, Ishrar NN, Dito I, te Pas AB. Initial respiratory support with cold, dry gas versus heated humidified gas and admission temperature of preterm infants. $J$ Pediatr. (2015) 166:245-50.e1. doi: 10.1016/j.jpeds.2014.09.049

14. East CE, Colditz PB, Begg LM, Brennecke SP. Update on intrapartum fetal pulse oximetry. Aust N Z J Obstet Gynaecol. (2002) 42:119-24.

15. Dawson JA, Kamlin CO, Vento M, Wong C, Cole TJ, Donath SM, et al. Defining the reference range for oxygen saturation for infants after birth. Pediatrics (2010) 125:e1340-7. doi: 10.1542/peds.2009-1510

16. Perlman JM, Wyllie J, Kattwinkel J, Atkins DL, Chameides L, Goldsmith JP, et al. Part 11: neonatal resuscitation: 2010 international consensus on cardiopulmonary resuscitation and emergency cardiovascular care science with treatment recommendations. Circulation (2010) 122 (16 Suppl. 2):S51638. doi: 10.1161/CIRCULATIONAHA.110.971127

17. Oei JL, Saugstad OD, Lui K, Wright IM, Smyth JP, Craven P, et al. Targeted oxygen in the resuscitation of preterm infants, a randomized clinical trial. Pediatrics (2017) 139:e20161452. doi: 10.1542/peds.2016-1452

18. Rook D, Schierbeek H, Vento $M$, Vlaardingerbroek $H$, van der Eijk AC, Longini $M$, et al. Resuscitation of preterm infants with different inspired oxygen fractions. J Pediatr. (2014) 164:1322-6.e3. doi: 10.1016/j.jpeds.2014.02.019

19. Oei JL, Finer NN, Saugstad OD, Wright IM, Rabi Y, Tarnow-Mordi W, et al. Outcomes of oxygen saturation targeting during delivery room stabilisation of preterm infants. Arch Dis Child Fetal Neonatal Ed. (2018) 103:F446-54. doi: 10.1136/archdischild-2016-312366

20. Rabi Y, Lodha A, Soraisham A, Singhal N, Barrington KJ, Shah PS. Outcomes of preterm infants following the introduction of room air resuscitation. Resuscitation (2015) 96:252-9. doi: 10.1016/j.resuscitation.2015.0 8.012

21. Dix LM, van Bel F, Lemmers PM. Monitoring cerebral oxygenation in neonates: an update. Front Pediatr. (2017) 5:46. doi: 10.3389/fped.2017.00046

22. Pichler G, Binder C, Avian A, Beckenbach E, Schmölzer GM, Urlesberger B. Reference ranges for regional cerebral tissue oxygen saturation and fractional oxygen extraction in neonates during immediate transition after birth. J Pediatr. (2013) 163:1558-63. doi: 10.1016/j.jpeds.2013.07.007

23. Pichler G, Urlesberger B, Baik N, Schwaberger B, Binder-Heschl C, Avian A, et al. Cerebral oxygen saturation to guide oxygen delivery in preterm neonates for the immediate transition after birth: a 2-center randomized controlled pilot feasibility trial. J Pediatr. (2016) 170:73-8.e1-4. doi: 10.1016/j.jpeds.2015.11.053

24. Hyttel-Sorensen S, Pellicer A, Alderliesten T, Austin T, van Bel F, Benders $\mathrm{M}$, et al. Cerebral near infrared spectroscopy oximetry in extremely preterm infants: phase II randomised clinical trial. BMJ (2015) 350:g7635. doi: 10.1136/bmj.g7635

25. Pichler G, Avian A, Binder C, Zotter H, Schmölzer GM, Morris N, et al. aEEG and NIRS during transition and resuscitation after birth: promising addi- tional tools; an observational study. Resuscitation (2013) 84:974-8. doi: 10.1016/j.resuscitation.2012.12.025

26. Pichler G, Cheung PY, Aziz K, Urlesberger B, Schmölzer GM. How to monitor the brain during immediate neonatal transition and resuscitation? A systematic qualitative review of the literature. Neonatology (2014) 105:205-10. doi: $10.1159 / 000357162$
27. Binder C, Urlesberger B, Avian A, Pocivalnik M, Müller W, Pichler G. Cerebral and peripheral regional oxygen saturation during postnatal transition in preterm neonates. J Pediatr. (2013) 163:394-9. doi: 10.1016/j.jpeds.2013.01.026

28. Cerebral Regional Tissue Oxygen Saturation to Guide Oxygen Delivery in Preterm Neonates During Immediate Transition After Birth: An Investigatorinitiated Randomised Multi-centre Multinational Clinical Trial (COSGOD III). (2017). (Accessed from clinicaltrials.gov, NCT No. NCT03166722)

29. Aziz K, Chadwick M, Baker M, Andrews W. Ante- and intra-partum factors that predict increased need for neonatal resuscitation. Resuscitation (2008) 79:444-52. doi: 10.1016/j.resuscitation.2008.08.004

30. Schmölzer GM, te Pas AB, Davis PG, Morley CJ. Reducing lung injury during neonatal resuscitation of preterm infants. J Pediatr. (2008) 153:741-5. doi: 10.1016/j.jpeds.2008.08.016

31. Klingenberg C, Wheeler KI, McCallion N, Morley CJ, Davis PG. Volumetargeted versus pressure-limited ventilation in neonates. Cochrane Database Syst Rev. (2017) 10:CD003666. doi: 10.1002/14651858.CD003666

32. Polglase GR, Miller SL, Barton SK, Baburamani AA, Wong FY, Aridas JD, et al. Initiation of resuscitation with high tidal volumes causes cerebral hemodynamic disturbance, brain inflammation and injury in preterm lambs. PLoS ONE (2012) 7:e39535. doi: 10.1371/journal.pone.0039535

33. Blank DA, Polglase GR, Kluckow M, Gill AW, Crossley KJ, Moxham A, et al. Haemodynamic effects of umbilical cord milking in premature sheep during the neonatal transition. Arch Dis Child Fetal Neonatal Ed. (2017) 5:fetalneonatal-2017-314005. doi: 10.1136/archdischild-2017-314005

34. Bhatt S, Alison B, Wallace EM, Crossley KJ, Gill AW, Kluckow M, et al. Delaying cord clamping until ventilation onset improves cardiovascular function at birth in preterm lambs. J Physiol. (2013) 591:2113-26. doi: 10.1113/jphysiol.2012.250084

35. Polglase GR, Blank DA, Barton SK, Miller SL, Stojanovska V, Kluckow $\mathrm{M}$, et al. Physiologically based cord clamping stabilises cardiac output and reduces cerebrovascular injury in asphyxiated near-term lambs. Arch Dis Child Fetal Neonatal Ed. (2017) 30:fetalneonatal-2017-313657. doi: 10.1136/archdischild-2017-313657

36. Fogarty M, Osborn DA, Askie L, Seidler AL, Hunter K, Lui K, et al. Delayed vs early umbilical cord clamping for preterm infants: a systematic review and meta-analysis. Am J Obstet Gynecol. (2018) 218:1-18. doi: 10.1016/j.ajog.2017.10.231

37. Tarnow-Mordi W, Morris J, Kirby A, Robledo K, Askie L, Brown R, et al. Delayed versus immediate cord clamping in preterm infants. $N$ Engl J Med. (2017) 377:2445-55. doi: 10.1056/NEJMoa1711281

38. Katheria AC, Leone TA, Woelkers D, Garey DM, Rich W, Finer NN. The effects of umbilical cord milking on hemodynamics and neonatal outcomes in premature neonates. J Pediatr. (2014) 164:1045-50. doi: 10.1016/j.jpeds.2014.01.024

39. Katheria AC, Truong G, Cousins L, Oshiro B, Finer NN. Umbilical cord milking versus delayed cord clamping in preterm infants. Pediatrics (2015) 136:61-9. doi: 10.1542/peds.2015-0368

40. Katheria A, Garey D, Truong G, Akshoomoff N, Steen J, Maldonado M, et al. A randomized clinical trial of umbilical cord milking vs delayed cord clamping in preterm infants: neurodevelopmental outcomes at 22-26 months of corrected age. J Pediatr. (2018) 194:76-80. doi: 10.1016/j.jpeds.2017.10.037

41. Polglase GR, Dawson JA, Kluckow M, Gill AW, Davis PG, te Pas AB, et al. Ventilation onset prior to umbilical cord clamping (physiological-based cord clamping) improves systemic and cerebral oxygenation in preterm lambs. PLoS ONE (2015) 10:e0117504. doi: 10.1371/journal.pone.0117504

42. Winter J, Kattwinkel J, Chisholm C, Blackman A, Wilson S, Fairchild K. Ventilation of preterm infants during delayed cord clamping (ventfirst): a pilot study of feasibility and safety. Am J Perinatol. (2017) 34:111-6. doi: 10.1055/s-0036-1584521

43. Duley L, Dorling J, Pushpa-Rajah A, Oddie SJ, Yoxall CW, Schoonakker $\mathrm{B}$, et al. Randomised trial of cord clamping and initial stabilisation at very preterm birth. Arch Dis Child Fetal Neonatal Ed. (2018) 103:F6-14. doi: 10.1136/archdischild-2016-312567

44. Lefebvre C, Rakza T, Weslinck N, Vaast P, Houfflin-Debarge V, Mur S, et al. Feasibility and safety of intact cord resuscitation in newborn infants with congenital diaphragmatic hernia (CDH). Resuscitation (2017) 120:20-5. doi: 10.1016/j.resuscitation.2017.08.233 
45. VentFirst: A Multicenter RCT of Assisted Ventilation During Delayed Cord Clamping for Extremely Preterm Infants. ClinicalTrials.gov Identifier: NCT02742454

46. Schmölzer GM, Kamlin COF, O’Donnell CPF, Dawson JA, Morley CJ, Davis PG. Assessment of tidal volume and gas leak during mask ventilation of preterm infants in the delivery room. Arch Dis Child Fetal Neonatal (2010) 95:F393-7. doi: 10.1136/adc.2009.174003

47. Kaufman J, Schmölzer GM, Kamlin CO, Davis PG. Mask ventilation of preterm infants in the delivery room. Arch Dis Child Fetal Neonatal Ed. (2013) 98:F405-10. doi: 10.1136/archdischild-2012-303313

48. van Vonderen JJ, van Zanten HA, Schilleman K, Hooper SB, Kitchen MJ, Witlox RS, et al. Cardiorespiratory monitoring during neonatal resuscitation for direct feedback and audit. Front Pediatr. (2016) 4:38. doi: $10.3389 /$ fped.2016.00038

49. Poulton DA, Schmölzer GM, Morley CJ, Davis PG. Assessment of chest rise during mask ventilation of preterm infants in the delivery room. Resuscitation (2011) 82:175-9. doi: 10.1016/j.resuscitation.2010.10.012

50. Schmölzer GM, Kamlin OC, Dawson JA, te Pas AB, Morley CJ, Davis PG. Respiratory monitoring of neonatal resuscitation. Arch Dis Child Fetal Neonatal Ed. (2010) 95:F295-303. doi: 10.1136/adc.2009.165878

51. Schilleman K, Witlox RS, van Vonderen JJ, Roegholt E, Walther FJ, te Pas AB. Auditing documentation on delivery room management using video and physiological recordings. Arch Dis Child Fetal Neonatal Ed. (2014) 99:F485-90. doi: 10.1136/archdischild-2014-306261

52. Schilleman K, van der Pot CJ, Hooper SB, Lopriore E, Walther FJ, te Pas AB. Evaluating manual inflations and breathing during mask ventilation in preterm infants at birth. J Pediatr. (2013) 162:457-63. doi: 10.1016/j.jpeds.2012.09.036

53. Schilleman K, Siew ML, Lopriore E, Morley CJ, Walther FJ, te Pas AB. Auditing resuscitation of preterm infants at birth by recording video and physiological parameters. Resuscitation (2012) 83:1135-9. doi: 10.1016/j.resuscitation.2012.0 1.036

54. van Vonderen JJ, Hooper SB, Krabbe VB, Siew ML, te Pas AB. Monitoring tidal volumes in preterm infants at birth: mask versus endotracheal ventilation. Arch Dis Child Fetal Neonatal Ed. (2015) 100:F43-6. doi: 10.1136/archdischild-2014-306614

55. Mian QN, Pichler G, Binder C, O’Reilly M, Aziz K, Urlesberger B, et al. Tidal volumes in spontaneously breathing preterm infants supported with continuous positive airway pressure. J Pediatr. (2014) 165:702-6.e1. doi: 10.1016/j.jpeds.2014.06.047

56. Kang LJ, Cheung PY, Pichler G, O’Reilly M, Aziz K, Schmölzer GM. Monitoring lung aeration during respiratory support in preterm infants at birth. PLoS ONE (2014) 9:e102729. doi: 10.1371/journal.pone.0102729

57. Schmölzer GM, Morley CJ, Wong C, Dawson JA, Kamlin CO, Donath $\mathrm{SM}$, et al. Respiratory function monitor guidance of mask ventilation in the delivery room: a feasibility study. J Pediatr. (2012) 160:377-81.e2. doi: 10.1016/j.jpeds.2011.09.017

58. Flynn JT, Bancalari E, Snyder ES, Goldbert RN, Feuer W, Cassady J, et al. A cohort study of transcutaneous oxygen tension and the incidence and severity of retinopathy of prematurity. N Engl J Med. (1992) 326:1050-4. doi: 10.1056/NEJM199204163261603

59. Collins MP, Lorenz JM, Jetton JR, Paneth N. Hypocapnia and other ventilation-related risk factors for cerebral palsy in low birth weight infants. Pediatr Res. (2001) 50:712-9. doi: 10.1203/00006450-200112000-00014

60. Askie LM, Henderson-Smart DJ, Irwig L, Simpson JM. Oxygen-saturation targets and outcomes in extremely preterm infants. N Engl J Med. (2003) 349:959-67. doi: 10.1056/NEJMoa023080

61. Supplemental Therapeutic Oxygen for Prethreshold Retinopathy of Prematurity (STOP-ROP), A Randomized, Controlled Trial. I: Primary Outcomes, The STOP-ROP Multicenter Study Group. Pediatrics (2000) 105:295-310. doi: 10.1542/peds.105.2.295

62. Hallenberger A, Poets CF, Horn W, Seyfang A, Urschitz MS, CLAC Study Group. Closed-loop automatic oxygen control (CLAC) in preterm infants: a randomized controlled trial. Pediatrics (2014) 133:e379-85. doi: $10.1542 /$ peds.2013-1834

63. van den Heuvel MEN, van Zanten HA, Bachman TE, te Pas AB, van Kaam AH, Onland W. Optimal target range of closed-loop inspired oxygen support in preterm infants: a randomized cross-over study. J Pediatr. (2018) 197:36-41. doi: $10.1016 /$ j.jpeds.2018.01.077

64. Tamussino A, Urlesberger B, Baik N, Schwaberger B, Binder-Heschl C, Schmölzer GM, et al. Low cerebral activity and cerebral oxygenation during immediate transition in term neonates-A prospective observational study. Resuscitation (2016) 103:49-53. doi: 10.1016/j.resuscitation.2016.03.011

65. Endesfelder S, Weichelt U, Strauß E, Schlör A, Sifringer M, Scheuer T, et al. Neuroprotection by caffeine in hyperoxia-induced neonatal brain injury. Int $J$ Mol Sci. (2017) 18:E187. doi: 10.3390/ijms18010187

66. Endesfelder S, Zaak I, Weichelt U, Bührer C, Schmitz T. Caffeine protects neuronal cells against injury caused by hyperoxia in the immature brain. Free Radic Biol Med. (2014) 67:221-34. doi: 10.1016/j.freeradbiomed.2013.09.026

67. Schmidt B, Roberts RS, Davis P, Doyle LW, Barrington KJ, Ohlsson A, et al. Long-term effects of caffeine therapy for apnea of prematurity. $N$ Engl J Med. (2007) 357:1893-902. doi: 10.1056/NEJMoa073679

68. Schmidt B, Roberts RS, Davis P, Doyle LW, Barrington KJ, Ohlsson A, et al. Caffeine therapy for apnea of prematurity. caffeine for apnea of prematurity trial group. N Engl J Med. (2006) 354:2112-21. doi: 10.1056/NEJMoa054065

69. Katheria AC, Sauberan JB, Akotia D, Rich W, Durham J, Finer NN. A pilot randomized controlled trial of early versus routine caffeine in extremely premature infants. Am J Perinatol. (2015) 32:879-86. doi: 10.1055/s-0034-1543981

70. Dekker J, Hooper SB, van Vonderen JJ, Witlox RSGM, Lopriore E, te Pas AB. Caffeine to improve breathing effort of preterm infants at birth: a randomized controlled trial. Pediatr Res. (2017) 82:290-6. doi: 10.1038/pr.2017.45

71. Dzietko M, Derugin N, Wendland MF, Vexler ZS, Ferriero DM. Delayed VEGF treatment enhances angiogenesis and recovery after neonatal focal rodent stroke. Transl Stroke Res. (2013) 4:189-200. doi: 10.1007/s12975-012-0221-6

72. Chaudhari T, McGuire W. Allopurinol for preventing mortality and morbidity in newborn infants with hypoxic-ischaemic encephalopathy. Cochrane Database Syst Rev. (2012) 11:CD006817. doi: 10.1002/14651858.CD006817

73. Van Bel F, Shadid M, Moison RM, Dorrepaal CA, Fontijn J, Monteiro L, et al. Effect of allopurinol on postasphyxial free radical formation, cerebral hemodynamics, and electrical brain activity. Pediatrics (1998) 101:185-93. doi: 10.1542/peds.101.2.185

74. Brines ML, Ghezzi P, Keenan S, Agnello D, de Lanerolle NC, Cerami C, et al. Erythropoietin crosses the blood-brain barrier to protect against experimental brain injury. Proc Natl Acad Sci USA. (2000) 97:10526-31. doi: 10.1073/pnas.97.19.10526

75. Traudt CM, McPherson RJ, Bauer LA, Richards TL, Burbacher TM, McAdams $\mathrm{RM}$, et al. Concurrent erythropoietin and hypothermia treatment improve outcomes in a term nonhuman primate model of perinatal asphyxia. Dev Neurosci. (2013) 35:491-503. doi: 10.1159/000355460

76. Robertson NJ, Faulkner S, Fleiss B, Bainbridge A, Andorka C, Price D, et al. Melatonin augments hypothermic neuroprotection in a perinatal asphyxia model. Brain (2013) 136(Pt 1):90-105. doi: 10.1093/brain/aws285

77. Barton SK, Melville JM, Tolcos M, Polglase GR, McDougall ARA, Azhan $A$, et al. Human amnion epithelial cells modulate ventilation-induced white matter pathology in preterm lambs. Dev Neurosci. (2015) 37:338-48. doi: $10.1159 / 000371415$

78. Baik N, Urlesberger B, Schwaberger B, Schmölzer GM, Avian A, Pichler G. Cerebral haemorrhage in preterm neonates: does cerebral regional oxygen saturation during the immediate transition matter? Arch Dis Child Fetal Neonatal Ed. (2015) 100:F422-7. doi: 10.1136/archdischild-2014-307590

Conflict of Interest Statement: The authors declare that the research was conducted in the absence of any commercial or financial relationships that could be construed as a potential conflict of interest.

Copyright (C) 2018 Viaroli, Cheung, O'Reilly, Polglase, Pichler and Schmölzer. This is an open-access article distributed under the terms of the Creative Commons Attribution License (CC BY). The use, distribution or reproduction in other forums is permitted, provided the original author(s) and the copyright owner(s) are credited and that the original publication in this journal is cited, in accordance with accepted academic practice. No use, distribution or reproduction is permitted which does not comply with these terms. 